\title{
Hydroxyapatite Whisker Reinforced 63s Glass Scaffolds for Bone Tissue Engineering
}

\author{
Cijun Shuai, ${ }^{1,2}$ Yiyuan Cao, ${ }^{1}$ Chengde Gao, ${ }^{1}$ Pei Feng, ${ }^{1}$ Tao Xiao, ${ }^{2,3}$ and Shuping Peng ${ }^{4,5}$ \\ ${ }^{1}$ State Key Laboratory of High Performance Complex Manufacturing, Central South University, Changsha 410083, China \\ ${ }^{2}$ Orthopedic Biomedical Materials Institute, Central South University, Changsha 410001, China \\ ${ }^{3}$ Department of Orthopedics, The Second Xiangya Hospital, Central South University, Changsha 410001, China \\ ${ }^{4}$ Hunan Provincial Tumor Hospital and the Affiliated Tumor Hospital of Xiangya School of Medicine, \\ Central South University, Changsha 410006, China \\ ${ }^{5}$ School of Basic Medical Science, Central South University, Changsha 410078, China \\ Correspondence should be addressed to Shuping Peng; shuping@csu.edu.cn
}

Received 29 September 2014; Revised 4 January 2015; Accepted 19 January 2015

Academic Editor: Kibret Mequanint

Copyright ( 2015 Cijun Shuai et al. This is an open access article distributed under the Creative Commons Attribution License, which permits unrestricted use, distribution, and reproduction in any medium, provided the original work is properly cited.

\begin{abstract}
Bioactive glass $(\mathrm{BG})$ is widely used for bone tissue engineering. However, poor mechanical properties are the major shortcomings. In the study, hydroxyapatite nanowhisker (HANw) was used as a reinforcement to improve the mechanical properties. 63s glass/HANw scaffolds were successfully fabricated by selective laser sintering (SLS). It was found that the optimal compressive strength and fracture toughness were achieved when $10 \mathrm{wt} . \%$ HANw was added. This led to $36 \%$ increase in compressive strength and $83 \%$ increase in fracture toughness, respectively, compared with pure 63s glass scaffolds. Different reinforcement mechanisms were analyzed based on the microstructure investigation. Whisker bridging and whisker pulling-out were efficient in absorbing crack propagating energy, resulting in the improvement of the mechanical properties. Moreover, bioactivity and biocompatibility of the scaffolds were evaluated in vitro. The results showed that composite scaffolds with $10 \mathrm{wt}$ \% HANw exhibited good apatite-forming ability and cellular affinity.
\end{abstract}

\section{Introduction}

BG of the $\mathrm{SiO}_{2}-\mathrm{CaO}-\mathrm{P}_{2} \mathrm{O}_{5}$ system has attracted increasing attention as a promising bone scaffold material [1-3]. It can convert to hydroxyl-carbonate apatite (HCA) similar to the main mineral constituent of nature bone and bond firmly with surrounding tissues $[4,5]$. Calcium ions and phosphate ions, which are released from BG, can further promote osteogenesis and activate osteogenic gene expression [6]. In addition, recent studies have indicated that BG can also induce neovascularization, enhancing the body's selfrehabilitation capacity [7]. 63s glass, a new generation of BG with molar composition of $63 \% \mathrm{SiO}_{2}, 28 \% \mathrm{CaO}$, and $9 \%$ $\mathrm{P}_{2} \mathrm{O}_{5}$, has excellent bioactive and resorbent properties [810]. However, the poor mechanical properties have prevented it from further applications. Therefore, a considerable effort has been made to improve mechanical properties. Generally, reinforcement by ceramic particles or whiskers has been considered an effective way [11].

Hydroxyapatite (HA) is one of the most biocompatible ceramic materials which has been studied extensively and clinically used due to the good bioactivity, high osteoconductive, and excellent osteoblastic responses [12-14]. HA has similar mineral constituents to nature bones and can directly bond to the bone [15]. In addition, the latest work has shown that HANw and HA nanoparticle (HANp) were helpful in improving mechanical properties of polymers and calcium phosphate ceramics. Converse et al. investigated the effects of HANw reinforcement on mechanical properties of polyetheretherketone (PEEK) and found that elastic modulus and tensile strength could increase effectively [16]. Hong et al. added HANp into PLLA composite and found that tensile strength and bending strength had noticeable improvement [17]. Hu et al. studied porous $\beta$-TCP scaffolds reinforced 


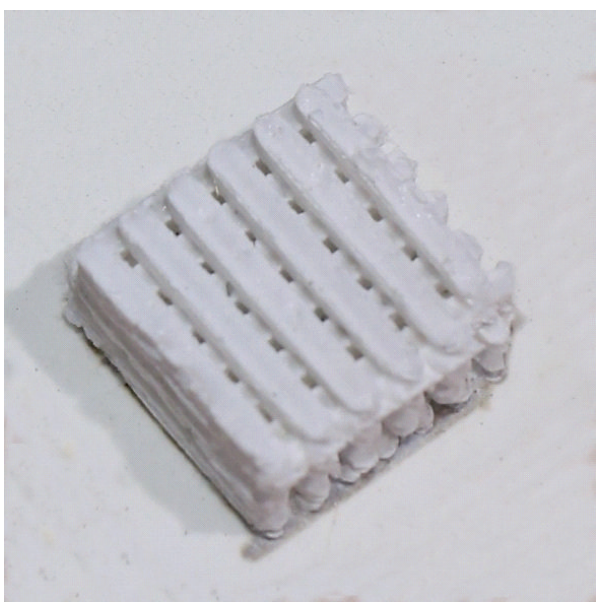

(a)

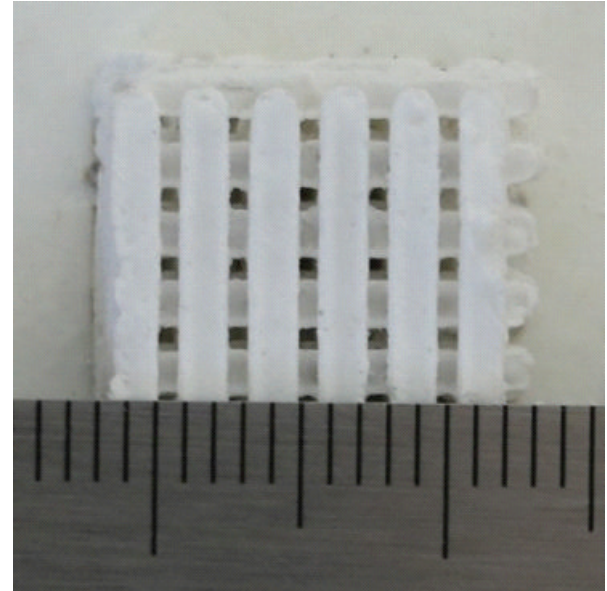

(b)

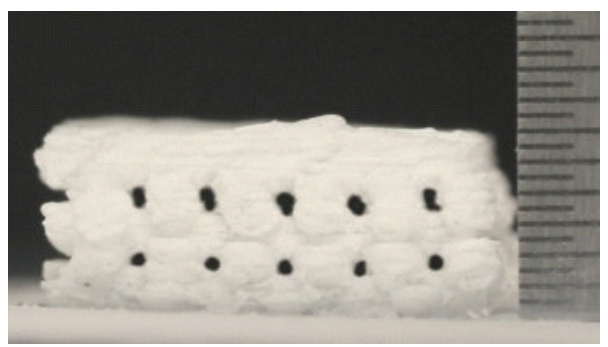

(c)

FIgURE 1: The porous 63s glass scaffolds with $10 \mathrm{wt} . \% \mathrm{HANw}$ (a) isometric view; (b) top view; (c) side view.

with HANw [18]. The results showed that HANw not only improved the mechanical properties but also enhanced bioactivity of the scaffolds.

In the present study, 63s glass/HANw scaffolds were manufactured by using SLS. For comparison, HANp added 63 s glass scaffolds had been also prepared. The influence of HANw on the microstructure and mechanical properties of $63 \mathrm{~s}$ glass scaffolds were investigated. The reinforcement mechanisms were also analyzed. In addition, bioactivity and biocompatibility of the scaffolds were evaluated in vitro.

\section{Materials and Methods}

2.1. Starting Materials. 63s glass (prepared by the sol-gel method) with a nominal chemical composition of $63 \% \mathrm{SiO}_{2}$, $28 \% \mathrm{CaO}$, and $9 \% \mathrm{P}_{2} \mathrm{O}_{5}$ in molar percentages was purchased from the KunShan Chinese Technology New Materials Co. Ltd. It is irregular in shape with an average size of $0.2-10 \mu \mathrm{m}$. Two different kinds of HA (nanowhisker and nanoparticle) were provided by Nanjing Emperor Nano Material Co. Ltd (China). The length and aspect ratio of the HANw are approximately 500 and $50 \mathrm{~nm}$, respectively. The average size of the HANp is $100 \mathrm{~nm}$.

2.2. Preparation of Composites. 63s glass/HANw composites with HANw contents of $0,5,10,15$ and 20 wt.\% were prepared using the following procedure: HANw was dispersed in ethanol and sonicated for $1 \mathrm{~h}$. Then 63 s glass powder, which was weighed in different amounts, was added to the HANw suspension and ball-milled for $12 \mathrm{~h}$ using $\mathrm{ZrO}_{2}$ balls as the grinding media. After mixing, the prepared mixture was dried at $353 \mathrm{~K}$ in an infrared stove to remove the liquid phases. Similarly, 63s glass/HANp composites with different weight ratio of $95 / 5,90 / 10,85 / 15$, and $80 / 20$ were also prepared.

2.3. Preparation of Scaffolds. A self-developed selective laser sintering system, as reported previously [19, 20], was used to prepare $3 \mathrm{D}$ porous composite scaffolds. It is made up of a $\mathrm{CO}_{2}$ laser with a focus system, a three-dimensional motion platform, and a corresponding control system. The $\mathrm{CO}_{2}$ laser, with a maximum output power of $100 \mathrm{~W}$, was purchased from SYNRAD Co. in USA. The minimum laser spot diameter can reach $100 \mu \mathrm{m}$ with the focus system. The $3 \mathrm{D}$ motion platform is driven by servomotor for precise positioning. The control system is available to determine the movements of $3 \mathrm{D}$ motion platform and the laser output power. Optimal SLS process parameters were chosen: laser power of $7.0 \mathrm{~W}$, laser spot diameter of $1.2 \mathrm{~mm}$, scan speed of $100.0 \mathrm{~mm} / \mathrm{min}$, and layer thickness of about $0.2 \mathrm{~mm}$. Then the porous scaffolds of uniform size $\left(15 \times 15 \times 6 \mathrm{~mm}^{3}\right)$ were fabricated. After removal of the unprocessed powder using compressed air, the interconnected porous structures were displayed in Figure 1. The porosity of the scaffolds was measured using the Archimedes method. The porosity can be calculated as $46.6 \pm 2.5 \%$ by the following [21]:

$$
P=\frac{\left(V_{a}-V_{t}\right)}{V_{a}} \times 100 \%,
$$


where $V_{a}$ is the apparent volume $\left(\mathrm{mm}^{3}\right), V_{t}$ is the true volume $\left(\mathrm{mm}^{3}\right)$, and $P$ is the porosity (\%).

2.4. Characterization. The morphology of the scaffolds was observed using SEM (TESCAN MIRA3 LMU, CO., Czech) equipped with an energy dispersive spectroscopy (EDS) instrument. The acceleration voltage applied was $20 \mathrm{kV}$. Before the SEM observations, the scaffolds were coated with platinum using a sputter coater (JFC-1600, JEOL CO., Japan). EDS analyses were performed to define the presence of HCA on the scaffolds surface after immersion in SBF. The functional group analyses were performed by FTIR with Nicolet 6700 spectrometer (Thermo Scientific Co. USA). The measurements were carried out in the mid-infrared range $\left(400-4000 \mathrm{~cm}^{-1}\right)$ at $0.6329 \mathrm{~cm} / \mathrm{s}$ mirror speed. The phase compositions of the scaffolds were evaluated using XRD (D8ADVANCE, Bruker AXS Inc., Germany) after ball-milling for $6 \mathrm{~h}$. The data were recorded in the interval $10^{\circ} \leq 2 \theta \leq 70^{\circ}$ at the rate of $2^{\circ}$ /min with $\mathrm{Cu}-\mathrm{K} \alpha$ radiation $(1.54056 \AA)$.

For the compressive strength tests, the 63s glass/HANw and $63 \mathrm{~s}$ glass/HANw composites with a thickness of $1.2 \mathrm{~mm}$ were prepared to rectangular strips, $\sim 1.3 \mathrm{~mm}$ width and $8 \mathrm{~mm}$ in length. The samples were loaded at a crosshead speed of $0.5 \mathrm{~mm} / \mathrm{min}$ using a universal testing machine (Shanghai Zhuoji instruments Co. LTD, China). The fracture toughness was evaluated by indentation with a Vickers hardness tester (HXD-1000TM/LCD, Digital Micro Hardness Tester, Shanghai Taiming Optical Instrument Co. Ltd). The samples $\left(8 \times 1.3 \times 1.2 \mathrm{~mm}^{3}\right)$ were inlaid in epoxy resin, polished with sandpaper, and subjected to indentation on the surfaces. The average values of fracture toughness were calculated from five tests. The fracture toughness $K_{i c}$ was determined using the following [22]:

$$
K_{i c}=0.0824 P c^{-3 / 2},
$$

where $P$ is the indentation load $(\mathrm{MN})$ and $c$ is the radial crack length $(\mathrm{m})$.

2.5. Bioactivity. The bioactivity of the $63 \mathrm{~s}$ glass scaffolds with $10 \mathrm{wt} . \% \mathrm{HANw}$ and $63 \mathrm{~s}$ glass scaffolds with $10 \mathrm{wt} . \%$ HANp was evaluated by examining HCA formation in SBF which was prepared as previously proposed by Kokubo and Takadama [23] and had similar ion concentrations to those in human blood plasma. Scaffolds with thickness of $6 \mathrm{~mm}$ and dimensions of $15 \times 15 \mathrm{~mm}^{2}$ were selected, and the ratio of solution volume to sample mass was kept constant at $1 \mathrm{~mL} \cdot \mathrm{mg}^{-1}$. The solutions with the samples were then kept in a shaking incubator at a controlled temperature of $36.5^{\circ} \mathrm{C}$ for 7 days. The SBF solutions were refreshed every $24 \mathrm{~h}$. After the preselected immersing time, the scaffolds were removed from SBF, gently rinsed with distilled water, and then dried in vacuum desiccators. The surface deposits were examined by FTIR spectroscopy and SEM equipped with EDS microanalysis.

2.6. Cell Culture. The MG-63 cells derived from human osteosarcoma (ATCC, Rockville, MD) were used in this study to evaluate the biocompatibility of the 63s glass scaffolds with $10 \mathrm{wt} . \% \mathrm{HANw}$ and 63 s glass scaffolds with $10 \mathrm{wt} . \%$ HANp (15 $\left.\times 15 \times 6 \mathrm{~mm}^{3}\right)$. The cells were seeded in $50 \mathrm{~mL}$ culture flask with fresh culture media supplemented with $10 \%$ fetal bovine serum (FBS, ATCC), $100 \mu \mathrm{g} / \mathrm{mL}$ streptomycin, and $100 \mathrm{U} / \mathrm{mL}$ penicillin at $37^{\circ} \mathrm{C}$ in a humid atmosphere of $5 \% \mathrm{CO}_{2}$. Before confluence, the cells were detached with trypsin/EDTA and resuspended in the medium. The scaffolds were sterilized by $75 \%$ ethanol and rinsed with phosphate-buffered saline (PBS). Then the cells at a concentration of $5 \times 10^{3}$ cells $/ \mathrm{cm}^{2}$ were added to the prewetted scaffolds.

2.7. Cell Morphology. Cells morphology on composite scaffolds was assessed by SEM observation. After 5 days of culture. Scaffolds were washed with PBS to eliminate unattached cells and fixed with $2.5 \%$ glutaraldehyde for $2 \mathrm{~h}$. Following this, scaffolds of fixed cells were dehydrated in a series of graded ethanol (30, 50, 70, 95, and 100\%) and further dried using hexamethyldisilazane (HMDS). Dried scaffolds were then sputter-coated with gold and examined using SEM.

\section{Results and Discussion}

3.1. Microstructure. The microstructures of scaffolds were shown in Figure 2. A relatively smooth surface of 63 s glass scaffolds was presented in Figure 2(a). When 10 wt.\% HANw was added to the scaffolds, HANw was well-distributed (Figure 2(c)). With further increase in HANw content, some agglomerates of whisker could be observed (Figures 2(d) and 2(e)). In addition, the diameter of the HANw on the scaffolds was rougher than that of HANw before sintering. The fact showed that the HANw was coated with 63 s glass, indicating strong interface physical bonding between amorphous 63s glass and HANw. On the other hand, the HANp was uniformly dispersed in the $63 \mathrm{~s}$ glass matrix when the HANp content reached $5 \mathrm{wt}$ \% (Figure 2(f)). As the HANp further increased, aggregates and loosely embedded HANp could be observed due to its high specific surface area, especially for highly filled composites.

The microstructures of $63 \mathrm{~s}$ glass scaffolds with and without reinforcement were further examined by using XRD (Figure 3). The results showed that no crystallization occurred in the XRD pattern of 63 s glass scaffolds (Figure 3(a)), which indicated that the 63s glass maintained amorphous state. The XRD pattern of 63s glass scaffolds reinforced with HANw (Figures 3(b) and 3(c)) or with HANp (Figures $3(\mathrm{~d})$ and $3(\mathrm{e})$ ) both had common diffraction peaks at $2 \theta$ degree of $25.9^{\circ}(002), 31.8^{\circ}(211), 32.9^{\circ}$ (300), and $34.1^{\circ}$ (202) and was in good agreement with standard hydroxyapatite PDF Card (no. 9-432). No impurity phase was observed, which demonstrated that no reaction occurred between $63 \mathrm{~s}$ glass and HA. In addition, the peaks intensity of HANw or HANp became stronger with the increasing content of $\mathrm{HANw}$ or HANp.

3.2. Mechanical Properties. The effect of HANw or HANp on the compressive strength and fracture toughness of the scaffolds was shown in Figure 4. The compressive 


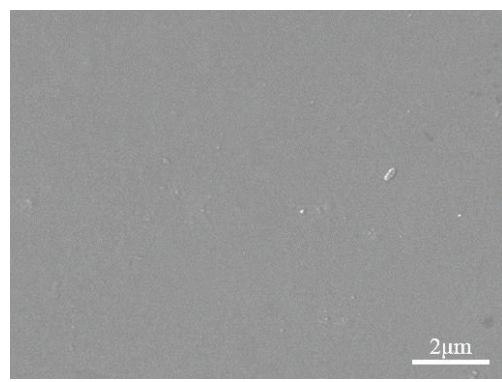

(a)

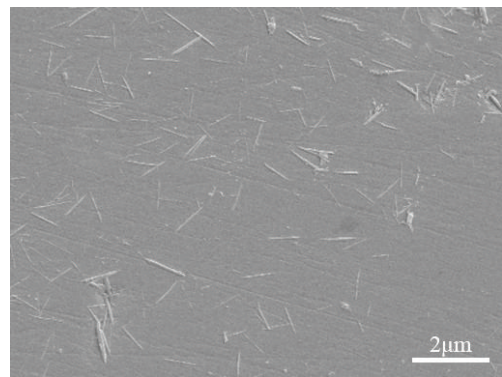

(d)

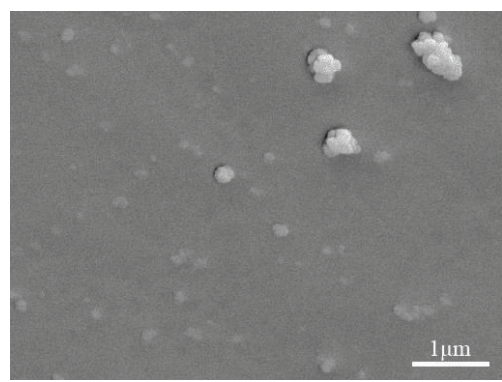

$(\mathrm{g})$

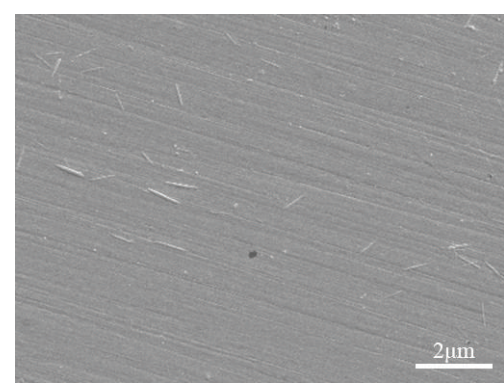

(b)

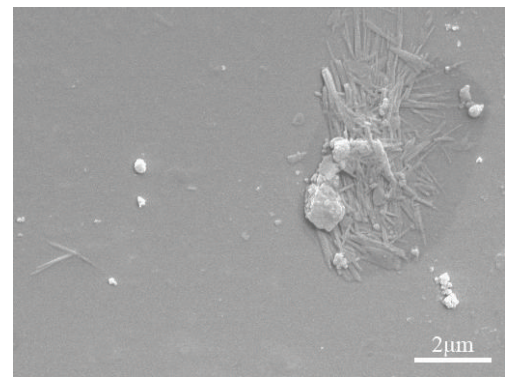

(e)

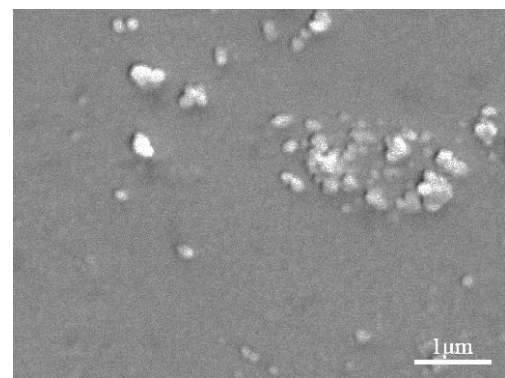

(h)

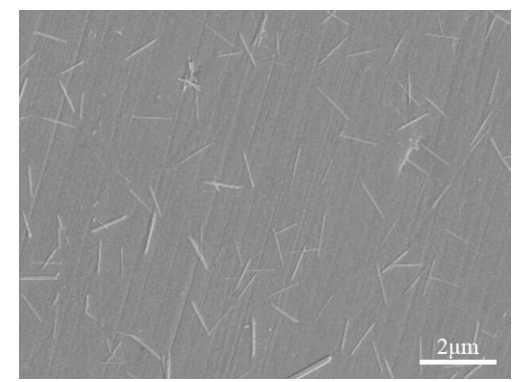

(c)

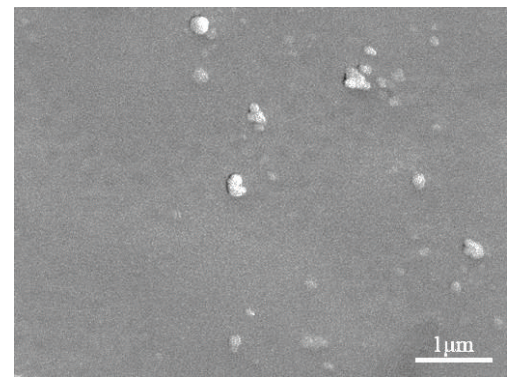

(f)

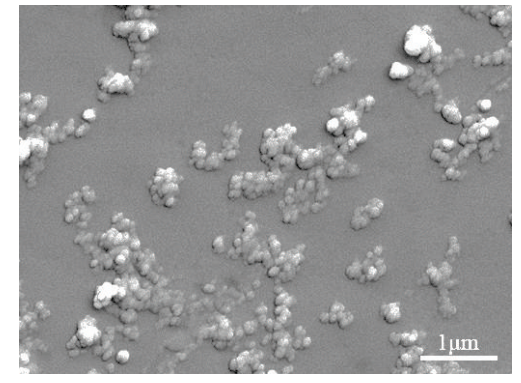

(i)

Figure 2: SEM micrograph of 63 s glass/HANw scaffolds containing (a) 0 wt.\%, (b) 5 wt.\%, (c) 10 wt.\%, (d) 15 wt.\%, (e) 20 wt.\% HANw and 63s glass/HANp scaffolds containing, (f) $5 \mathrm{wt} . \%$, (g) $10 \mathrm{wt} . \%$, (h) $15 \mathrm{wt} . \%$, and (i) $20 \mathrm{wt} . \%$ HANp.

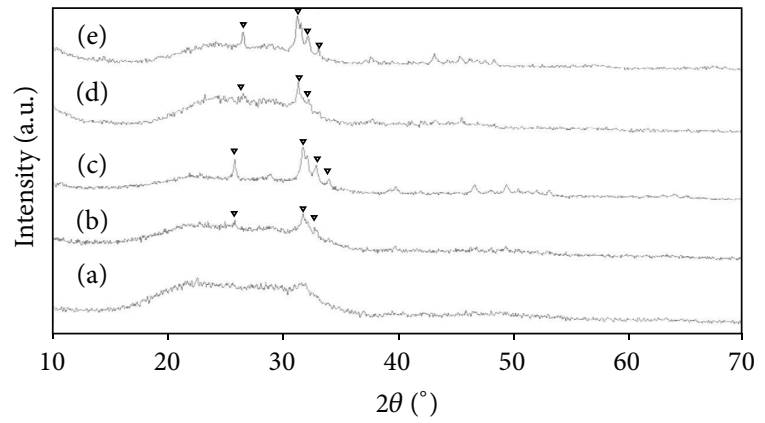

- HA

FIGURE 3: XRD patterns of (a) $63 \mathrm{~S}$ glass scaffolds, $63 \mathrm{~s}$ glass/HANw scaffolds with different HANw contents of (b) $5 \mathrm{wt} . \%$, (c) $15 \mathrm{wt} . \%, 63 \mathrm{~s}$ glass/HANp scaffolds with different HANp contents of (d) $5 \mathrm{wt} . \%$, (e) 15 wt.\%.

strength increased linearly firstly and then decreased slightly (Figure 4(a)). The highest compressive strength of $63 \mathrm{~s}$
glass/HANw scaffolds was $23.69 \mathrm{MPa}$, when the content of $\mathrm{HANw}$ increased to $10 \%$, while it was $19.21 \mathrm{MPa}$ for 63s glass/HANp scaffolds. This was about $36 \%$ increase in compressive strength for the scaffolds with $10 \mathrm{wt} . \% \mathrm{HANw}$ addition compared with that of the pure 63 s glass scaffolds. The decrease of compressive strength with addition of HANw or HANp more than $10 \mathrm{wt}$ \% was attributed to the agglomeration of HANw or HANp.

The peak values of fracture toughness were found for HANw and HANp at $10 \mathrm{wt}$ \% (Figure 4(b)). The HANw gave a significantly greater increase in fracture toughness than did the HANp. The maximum fracture toughness obtained from the $63 \mathrm{~s}$ glass/HANw scaffolds was $1.36 \mathrm{MPa} \cdot \mathrm{m}^{1 / 2}$ and that of $63 \mathrm{~s}$ glass/HANp scaffolds was $0.95 \mathrm{MPa} \cdot \mathrm{m}^{1 / 2}$. It suggested that HANw was more efficient in improving the mechanical properties of 63s glass scaffolds than HANp. The compressive strength of the $63 \mathrm{~s}$ glass scaffolds with $10 \mathrm{wt} . \% \mathrm{HANw}$ was higher than that of cancellous bone (0.1-16 MPa) [24]. The fracture toughness was a little lower than that of cortical bone $\left(2-12 \mathrm{MPa} \cdot \mathrm{m}^{1 / 2}\right)$ [25]. Fu et al. applied a polymer foam 


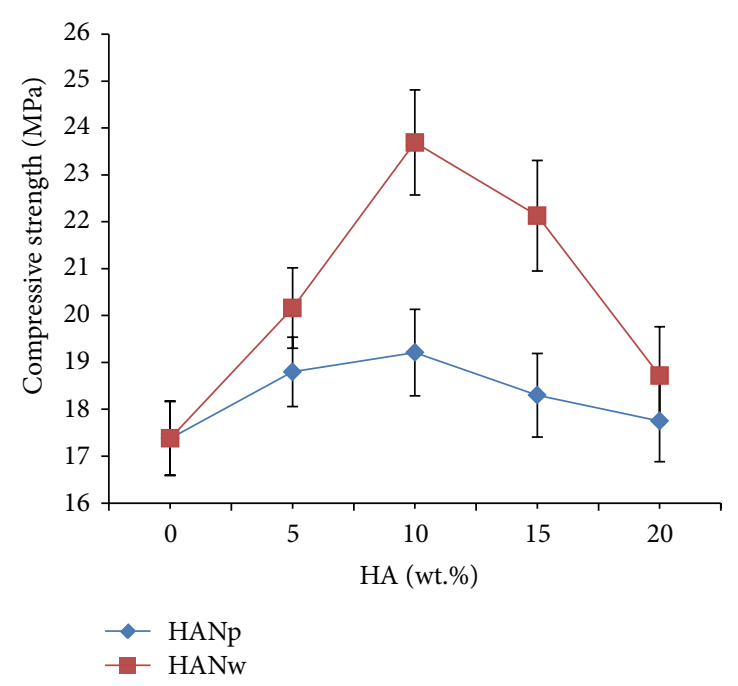

(a)

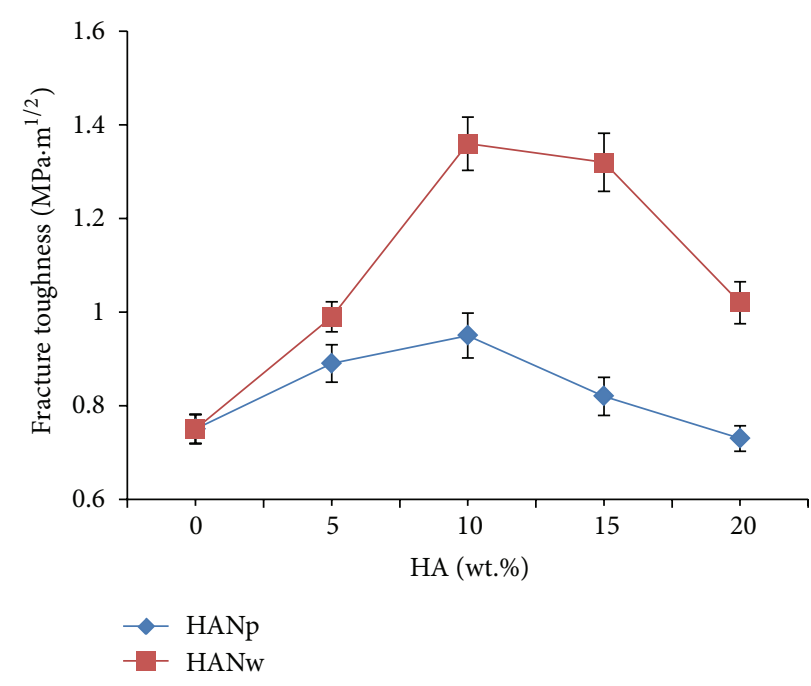

(b)

Figure 4: Mechanical properties of the 63s glass/HANw scaffolds and the 63s glass/HANp scaffolds: compressive strength and (b) fracture toughness.

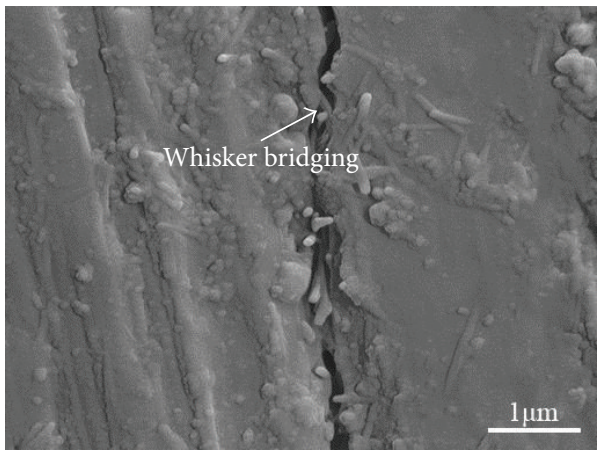

(a)

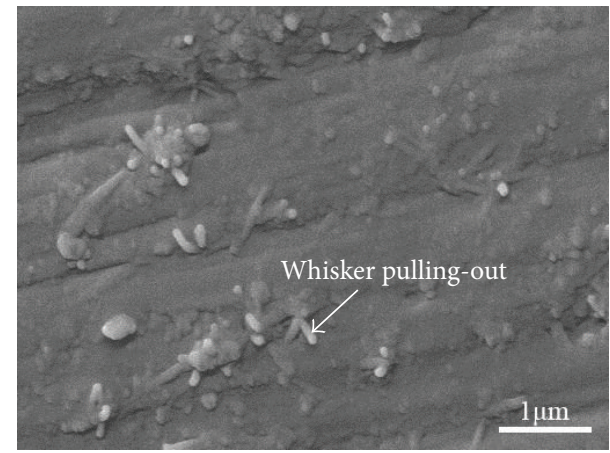

(b)

FIGURE 5: Toughening mechanism of 63s glass/HANw scaffolds: (a) indentation crack propagation, (b) fracture surface.

replication technique to prepare the 13-93 bioactive glass scaffolds (porosity of $85 \pm 2 \%$, pore size of $100-500 \mu \mathrm{m}$ ) [26]. The compressive strength of the obtained scaffolds was $11 \pm$ $1 \mathrm{MPa}$. Yazdanpanah et al. used $30 \mathrm{wt} . \%$ of nanocrystalline forsterite to improve the fracture toughness of BG [27]. The fracture toughness was $0.22 \mathrm{MPa} \cdot \mathrm{m}^{1 / 2}$.

To better illustrate the reinforcement mechanisms, the micrograph of crack propagation of 63s glass scaffolds with HANw was presented in Figure 5(a). The whisker bridging in the crack propagation path could be observed clearly. When the matrix was subjected to crack-forming stresses, partial debonding of the whiskers along the crack line occurred to form whisker bridging. In other words, the continuous propagates of microcracks would be inhibited so that the interfacial fracture energy was consumed during this process. As the stress and size of the displacement further increased, the whisker pulling-out became the primary reinforcement mechanism. Fracture surface of the scaffolds was presented in Figure 5(b). On the fracture surface, a number of HANw pulled out from the 63s glass matrix. Moreover, the breakage of HANw also occurred. This indicated that HANw had a strong interfacial bonding with the $63 \mathrm{~s}$ glass so that the fracture did not occur preferentially at the 63s glass/HANw interface.

It was believed that the incorporate effects of whisker bridging and whisker pulling-out absorbed crack propagating energy during fracture, which resulted in the improved fracture toughness. According to the mechanisms research, it could be known that the composite scaffolds with $10 \mathrm{wt} . \%$ HANw could obtain desirable results.

3.3. Formation of Apatite Layer. Surface morphology of composite scaffolds containing $10 \mathrm{wt} . \% \mathrm{HANw}$ and composite scaffolds containing $10 \mathrm{wt} . \%$ HANp soaked in SBF for 7 days was shown in Figure 6. Compared to the scaffolds before SBF (Figure 2), there was a mineral layer deposited on both scaffolds after SBF. At a higher magnification (Figures 6(b) 

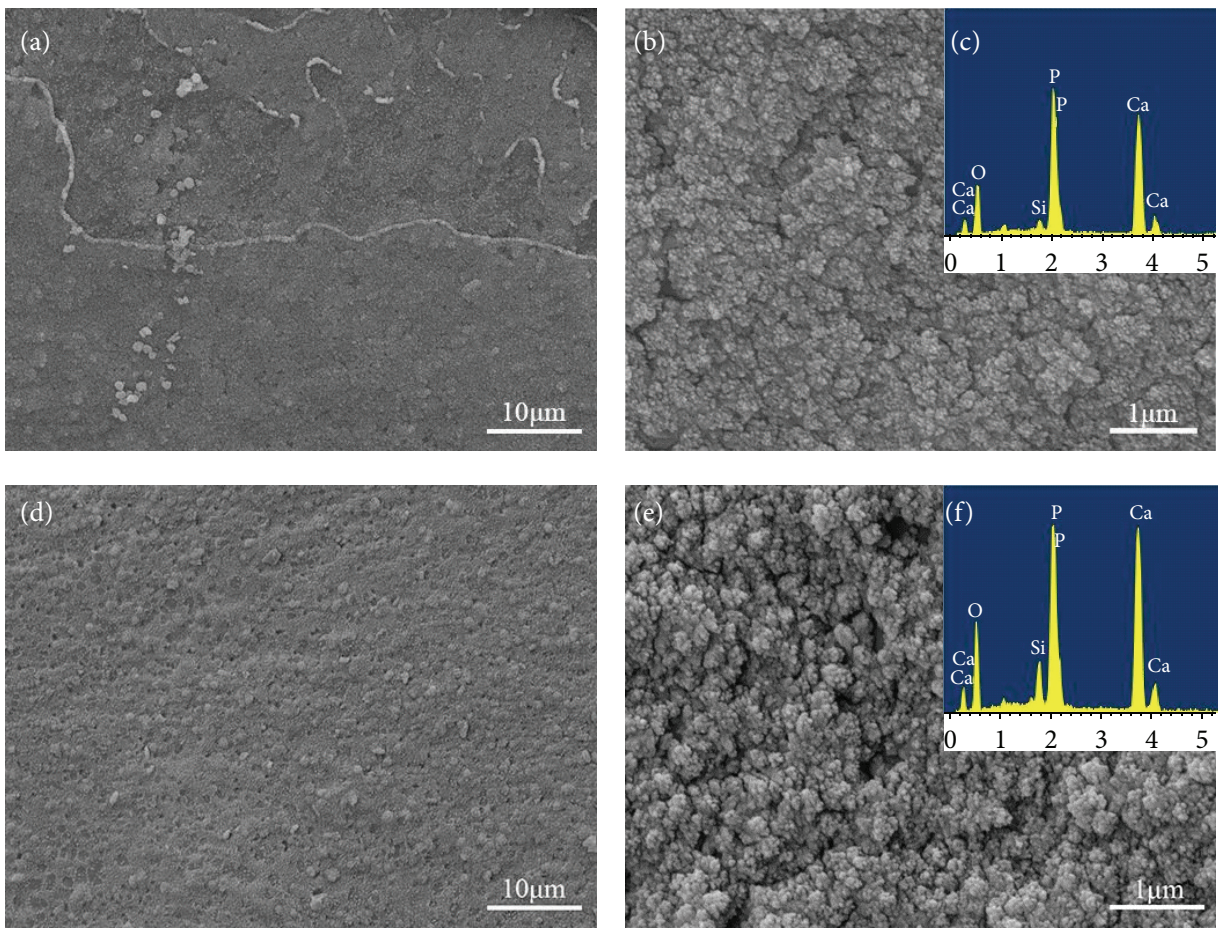

Figure 6: Microstructures of 63s scaffolds with 10 wt.\% HANw ((a) low and (b) high magnified image) and 10 wt.\% HANp ((d) low and (e) high magnified image) after immersion in SBF for 7 days: (a) low and (b) high magnified image. EDS of the mineral layer ((c) 63s glass/HANw scaffolds; (f) 63s glass/HANp scaffolds).

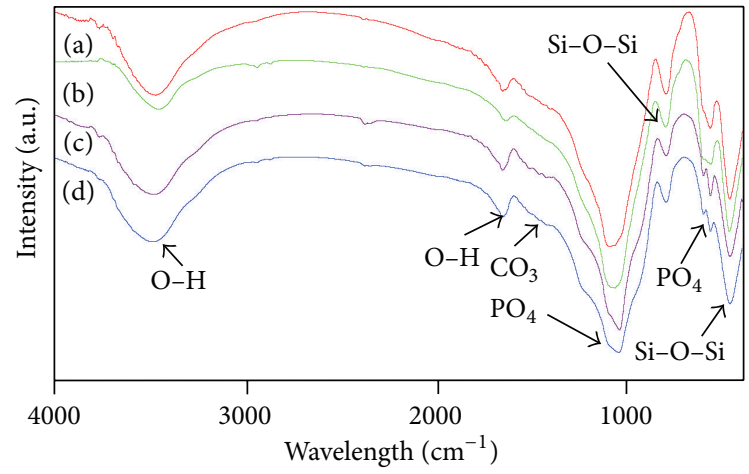

FIGURE 7: FTIR spectra of scaffolds made of 63 s glass with $10 \mathrm{wt} . \%$ HANw ((a) before and (c) after being soaked in SBF), 63s glass with 10 wt.\% HANp ((b) before and (d) after being soaked in SBF).

and 6(e)), the mineral layer on both surfaces seemed to be similar composed of a fine structure of nanoparticles with sizes in about $60 \mathrm{~nm}$.

EDS analysis (Figures 6(c) and 6(f)) of the mineral layer composition revealed a $\mathrm{Ca} / \mathrm{P}$ atomic ratio of 1.32 and 1.34 , respectively, which were close to the $\mathrm{Ca} / \mathrm{P}$ atomic ratio of physiological apatite (1.35-1.46) [28]. FTIR spectra of the 63s glass scaffolds with $10 \mathrm{wt} . \% \mathrm{HANw}$ and $63 \mathrm{~s}$ glass scaffolds with $10 \mathrm{wt} . \%$ HANp surfaces before soaking were shown in Figures 7(a) and 7(b), respectively. The bands at around 3455 and $1647 \mathrm{~cm}^{-1}$ are attributed to $\mathrm{O}-\mathrm{H}$ in adsorbed water [29]. The absorption peaks at 1039 and $601-566 \mathrm{~cm}^{-1}$ are assigned to $\nu 3$ and $\nu 4 \mathrm{PO}_{4}{ }^{3-}$ group [30, 31], respectively. The bands located at 800 and $464 \mathrm{~cm}^{-1}$ are ascribed to silicate group [32]. After soaking in SBF (Figures 7(c) and 7(d)), the intensity of $\mathrm{PO}_{4}{ }^{3-}$ absorption peak at $566 \mathrm{~cm}^{-1}$ was increased. Simultaneously, some carbonate absorption bands at around $1500 \mathrm{~cm}^{-1}$ could be recognized [33]. The results indicated that the new HCA layer was precipitating on both surfaces of the composites scaffolds during soaking in SBF.

3.4. Cell Morphology. The morphologies of MG-63 cells after 5 days of being cultured on the 63s glass scaffolds with $10 \mathrm{wt} . \%$ HANw and $63 \mathrm{~s}$ glass scaffolds with $10 \mathrm{wt} . \%$ HANp were shown in Figure 8. Attached cells on both scaffolds have the similar morphologies with polygonal appearance and numerous pseudopodia. This result indicated that cells can attach and spread well on both surfaces. Cells were also seen to connect to each other by forming extra cellular matrix (ECM), which plays a key role in cell migration and could be observed on both cells and scaffolds. Wide distribution of the ECM and continuous increase in cell aggregation indicated high cell activity on both composites scaffolds.

\section{Conclusions}

The 63s glass/HANw and 63s glass/HANp scaffolds with controllable porous architecture were manufactured by SLS, respectively. $63 \mathrm{~s}$ glass maintained its amorphous state after laser sintering. Owing to the uniform dispersion of HANw and the strong interface physical bonding between $63 \mathrm{~s}$ glass 


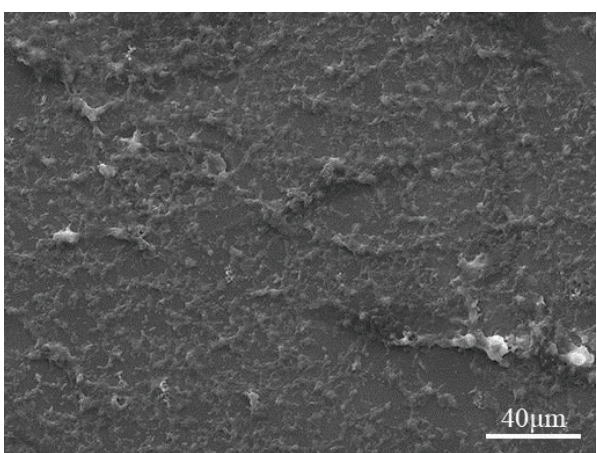

(a)

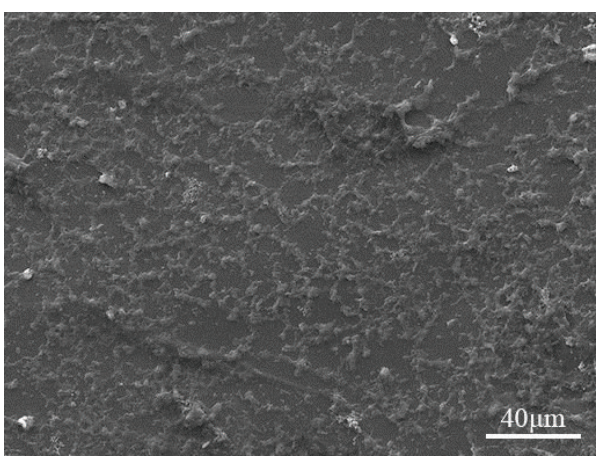

(c)

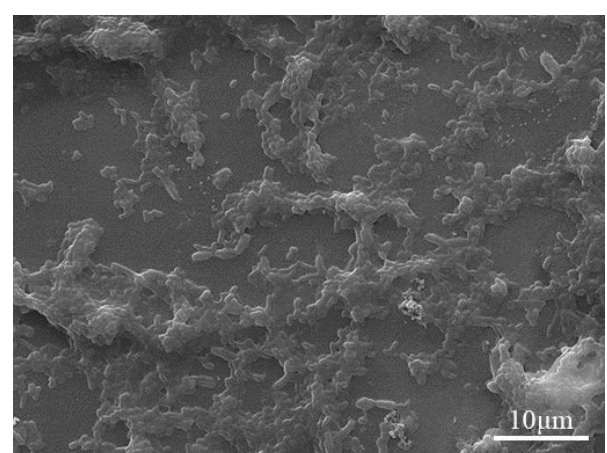

(b)

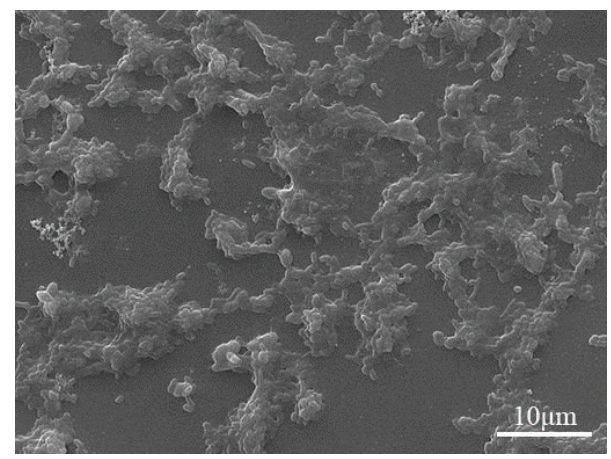

(d)

Figure 8: MG-63 cells cultured on 63s scaffolds with 10 wt.\% HANw ((a) low and (b) high magnified image) and 10 wt.\% HANp ((c) low and (d) high magnified image) for 5 days.

and HANw, the compressive strength and fracture toughness increased markedly with increasing HANw content from 0 to $10 \mathrm{wt} . \%$. The incorporate effects of whisker bridging and whisker pulling-out were also observed. The introduction of $10 \mathrm{wt} . \% \mathrm{HANw}$ to $63 \mathrm{~s}$ glass scaffolds can produce more effective improvements in mechanical properties than did HANp. Meanwhile, the scaffolds with 10 wt.\% HANw doping exhibited favorable apatite-forming bioactivity and excellent cellular biocompatibility. The results of all these studies indicated that HANw reinforced 63 s glass scaffolds could be an ideal candidate for bone tissue engineering.

\section{Conflict of Interests}

The authors declare that there is no conflict of interests regarding the publication of this paper.

\section{Acknowledgments}

This work was supported by the following funds: (1) the Natural Science Foundation of China (51222506, 81372366, and 81472058); (2) Overseas, Hong Kong \& Macao Scholars Collaborated Researching Fund of National Natural Science Foundation of China (81428018); (3) Hunan Provincial Natural Science Foundation of China (14JJ1006); (4) Project supported by the Fok Ying-Tong Education Foundation, China (131050); (5) Shenzhen Strategic Emerging Industrial Development Funds (JCYJ20130401160614372); (6) the
Open-End Fund for the Valuable and Precision Instruments of Central South University; (7) the faculty research grant of Central South University (2013JSJJ011, 2013JSJJ046); (8) State Key Laboratory of New Ceramic and Fine Processing Tsinghua University (KF201413).

\section{References}

[1] Q. Fu, E. Saiz, M. N. Rahaman, and A. P. Tomsia, "Bioactive glass scaffolds for bone tissue engineering: state of the art and future perspectives," Materials Science and Engineering C, vol. 31, no. 7, pp. 1245-1256, 2011.

[2] P. Saravanapavan, J. R. Jones, R. S. Pryce, and L. L. Hench, "Bioactivity of gel-glass powders in the $\mathrm{CaO}-\mathrm{SiO}_{2}$ system: a comparison with ternary $\left(\mathrm{CaO}-\mathrm{P}_{2} \mathrm{O}_{5}-\mathrm{SiO}_{2}\right)$ and quaternary glasses $\left(\mathrm{SiO}_{2}-\mathrm{CaO}-\mathrm{P}_{2} \mathrm{O}_{5}-\mathrm{Na}_{2} \mathrm{O}\right)$," Journal of Biomedical Materials Research Part A, vol. 66, no. 1, pp. 110-119, 2003.

[3] G. Malavasi, L. Menabue, M. C. Menziani, A. Pedone, A. J. Salinas, and M. Vallet-Regí, "New insights into the bioactivity of $\mathrm{SiO}_{2}-\mathrm{CaO}$ and $\mathrm{SiO}_{2}-\mathrm{CaO}-\mathrm{P}_{2} \mathrm{O}_{5}$ sol-gel glasses by molecular dynamics simulations," Journal of Sol-Gel Science and Technology, vol. 67, no. 1, pp. 208-219, 2013.

[4] M. D. O’Donnell, S. J. Watts, R. G. Hill, and R. V. Law, “The effect of phosphate content on the bioactivity of soda-limephosphosilicate glasses," Journal of Materials Science: Materials in Medicine, vol. 20, no. 8, pp. 1611-1618, 2009.

[5] P. N. De Aza, A. H. De Aza, P. Pena, and S. De Aza, "Bioactive glasses and glass-ceramics," Boletin de la Sociedad Espanola de Ceramica y Vidrio, vol. 46, no. 2, pp. 45-55, 2007. 
[6] P. Valerio, M. M. Pereira, A. M. Goes, and M. F. Leite, "The effect of ionic products from bioactive glass dissolution on osteoblast proliferation and collagen production," Biomaterials, vol. 25, no. 15, pp. 2941-2948, 2004.

[7] M. N. Rahaman, D. E. Day, B. Sonny Bal et al., "Bioactive glass in tissue engineering," Acta Biomaterialia, vol. 7, no. 6, pp. 23552373, 2011.

[8] A. Doostmohammadi, A. Monshi, M. H. Fathi, S. Karbasi, O. Braissant, and A. U. Daniels, "Direct cytotoxicity evaluation of $63 \mathrm{~S}$ bioactive glass and bone-derived hydroxyapatite particles using yeast model and human chondrocyte cells by microcalorimetry," Journal of Materials Science: Materials in Medicine, vol. 22, no. 10, pp. 2293-2300, 2011.

[9] M. Mehdikhani-Nahrkhalaji, M. H. Fathi, V. Mortazavi, S. B. Mousavi, and S. M. Razavi, "Subcutaneous connective tissue reactions to three types of bioactive glass nanopowders," Journal of Biomedical Nanotechnology, vol. 7, no. 3, pp. 460-465, 2011.

[10] M. Erol-Taygun, K. Zheng, and A. R. Boccaccini, "Nanoscale bioactive glasses in medical applications," International Journal of Applied Glass Science, vol. 4, no. 2, pp. 136-148, 2013.

[11] A. A. Zandinejad, M. Atai, and A. Pahlevan, "The effect of ceramic and porous fillers on the mechanical properties of experimental dental composites," Dental Materials, vol. 22, no. 4, pp. 382-387, 2006.

[12] Y. Abe, Y. Okazaki, K. Hiasa et al., "Bioactive surface modification of hydroxyapatite," BioMed Research International, vol. 2013, Article ID 626452, 9 pages, 2013.

[13] H. Zhou and J. Lee, "Nanoscale hydroxyapatite particles for bone tissue engineering," Acta Biomaterialia, vol. 7, no. 7, pp. 2769-2781, 2011.

[14] V. Uskoković and D. P. Uskoković, "Nanosized hydroxyapatite and other calcium phosphates: chemistry of formation and application as drug and gene delivery agents," Journal of Biomedical Materials Research-Part B Applied Biomaterials, vol. 96, no. 1, pp. 152-191, 2011.

[15] M. Pilia, T. Guda, and M. Appleford, "Development of composite scaffolds for load-bearing segmental bone defects," BioMed Research International, vol. 2013, Article ID 458253, 15 pages, 2013.

[16] G. L. Converse, W. Yue, and R. K. Roeder, "Processing and tensile properties of hydroxyapatite-whisker-reinforced polyetheretherketone," Biomaterials, vol. 28, no. 6, pp. 927-935, 2007.

[17] Z. Hong, P. Zhang, C. He et al., "Nano-composite of poly(Llactide) and surface grafted hydroxyapatite: mechanical properties and biocompatibility," Biomaterials, vol. 26, no. 32, pp. 6296-6304, 2005.

[18] H. Hu, G. Xu, Q. Zan et al., "In situ formation of nano-hydroxyapatite whisker reinfoced porous $\beta$-TCP scaffolds," Microelectronic Engineering, vol. 98, pp. 566-569, 2012.

[19] C. Shuai, C. Gao, Y. Nie, A. Hu, H. Qu, and S. Peng, "Structural design and experimental analysis of a selective laser sintering system with nano-hydroxyapatite powder," Journal of Biomedical Nanotechnology, vol. 6, no. 4, pp. 370-374, 2010.

[20] C. Shuai, P. Li, J. Liu, and S. Peng, "Optimization of TCP/HAP ratio for better properties of calcium phosphate scaffold via selective laser sintering," Materials Characterization, vol. 77, pp. 23-31, 2013.

[21] I. Zein, D. W. Hutmacher, K. C. Tan, and S. H. Teoh, "Fused deposition modeling of novel scaffold architectures for tissue engineering applications," Biomaterials, vol. 23, no. 4, pp. 11691185, 2002.
[22] X. Wang and C. M. Agrawal, "A mixed mode fracture toughness test of bone-biomaterial interfaces," Journal of Biomedical Materials Research, vol. 53, no. 6, pp. 664-672, 2000.

[23] T. Kokubo and H. Takadama, "How useful is SBF in predicting in vivo bone bioactivity?" Biomaterials, vol. 27, no. 15, pp. 29072915, 2006.

[24] B. L. Riggs, S. Khosla, and L. J. Melton III, "Better tools for assessing osteoporosis," The Journal of Clinical Investigation, vol. 122, no. 12, pp. 4323-4324, 2012.

[25] H.-W. Kim, J. C. Knowles, L.-H. Li, and H.-E. Kim, "Mechanical performance and osteoblast-like cell responses of fluorinesubstituted hydroxyapatite and zirconia dense composite," Journal of Biomedical Materials Research, Part A, vol. 72, no. 3, pp. 258-268, 2005.

[26] Q. Fu, M. N. Rahaman, B. Sonny Bal, R. F. Brown, and D. E. Day, "Mechanical and in vitro performance of 13-93 bioactive glass scaffolds prepared by a polymer foam replication technique," Acta Biomaterialia, vol. 4, no. 6, pp. 1854-1864, 2008.

[27] A. Yazdanpanah, R. Kamalian, F. Moztarzadeh, M. Mozafari, R. Ravarian, and L. Tayebi, "Enhancement of fracture toughness in bioactive glass-based nanocomposites with nanocrystalline forsterite as advanced biomaterials for bone tissue engineering applications," Ceramics International, vol. 38, no. 6, pp. 50075014, 2012.

[28] T. Dey, P. Roy, B. Fabry, and P. Schmuki, "Anodic mesoporous $\mathrm{TiO}_{2}$ layer on Ti for enhanced formation of biomimetic hydroxyapatite," Acta Biomaterialia, vol. 7, no. 4, pp. 1873-1879, 2011.

[29] X. Cai, H. Wang, Q. Zhang, and J. Tong, "Selective oxidation of styrene efficiently catalyzed by spinel $\mathrm{Mg}$-Cu ferrite complex oxides in water," Journal of Sol-Gel Science and Technology, vol. 69, no. 1, pp. 33-39, 2014.

[30] J. Venkatesan, Z. J. Qian, B. Ryu, N. V. Thomas, and S. K. Kim, "A comparative study of thermal calcination and an alkaline hydrolysis method in the isolation of hydroxyapatite from Thunnus obesus bone," Biomedical Materials, vol. 6, no. 3, Article ID 035003, 2011.

[31] R. Rajesh, A. Hariharasubramanian, N. Senthilkumar et al., "A biocompatible and load bearing composite of multi-walled carbon nanotubes chitosan and natural hydroxyapatite derived from the chicken bones wasted in the slaughter houses," International Journal of Pharmacy and Pharmaceutical Sciences, vol. 4, no. 4, pp. 716-720, 2012.

[32] A. G. Kalampounias, "IR and Raman spectroscopic studies of sol-gel derived alkaline-earth silicate glasses," Bulletin of Materials Science, vol. 34, no. 2, pp. 299-303, 2011.

[33] G. Miao, X. Chen, H. Dong et al., "Investigation of emulsified, acid and acid-alkali catalyzed mesoporous bioactive glass microspheres for bone regeneration and drug delivery," Materials Science and Engineering C, vol. 33, no. 7, pp. 42364243, 2013. 


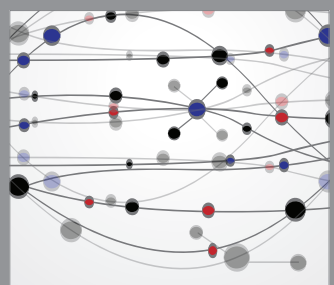

The Scientific World Journal
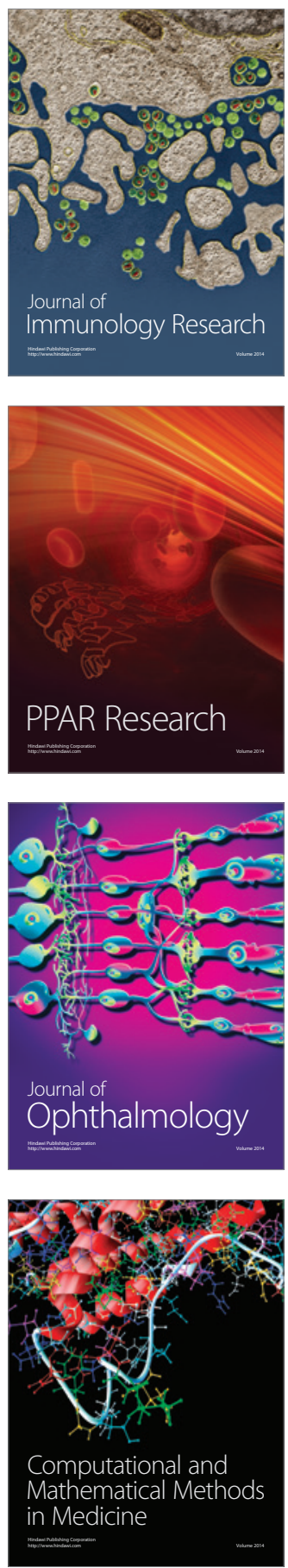

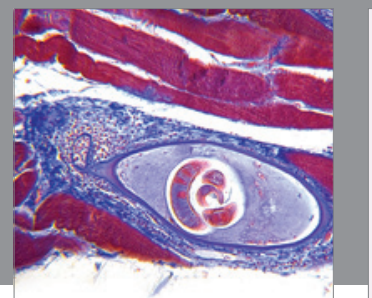

Gastroenterology

Research and Practice
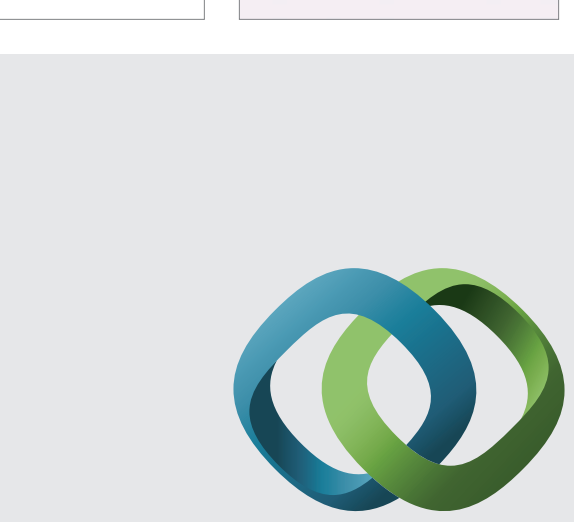

\section{Hindawi}

Submit your manuscripts at

http://www.hindawi.com
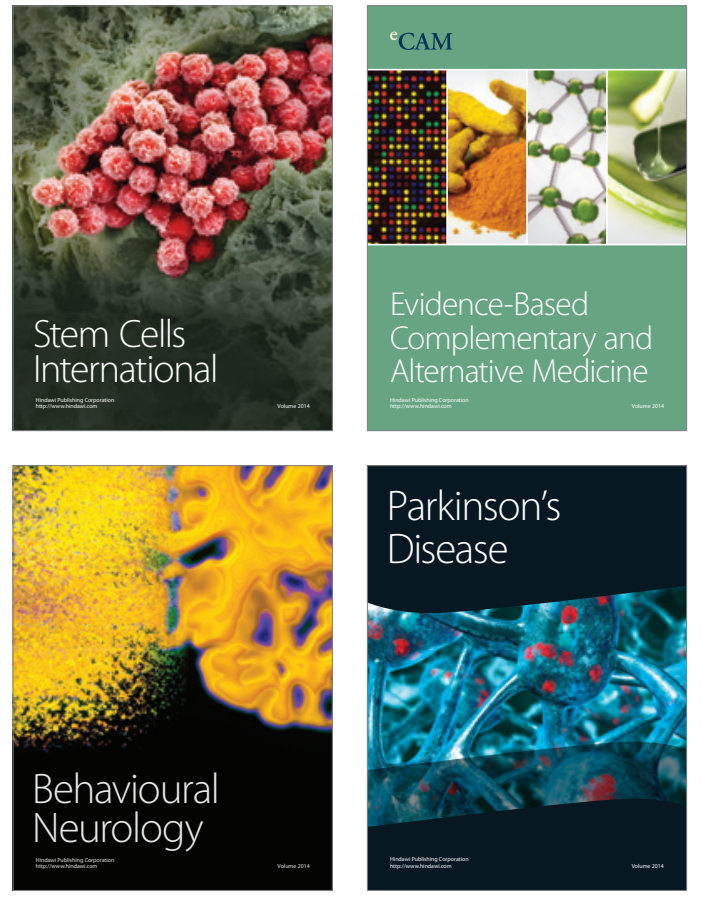
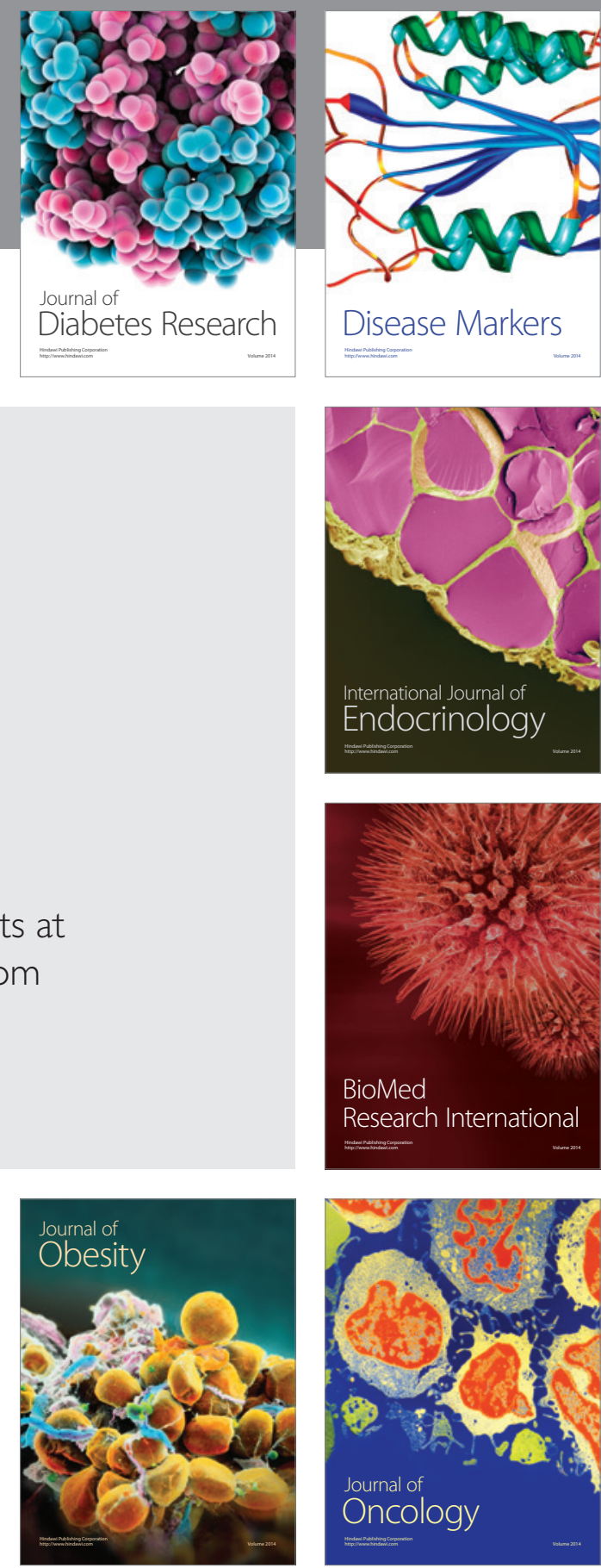

Disease Markers
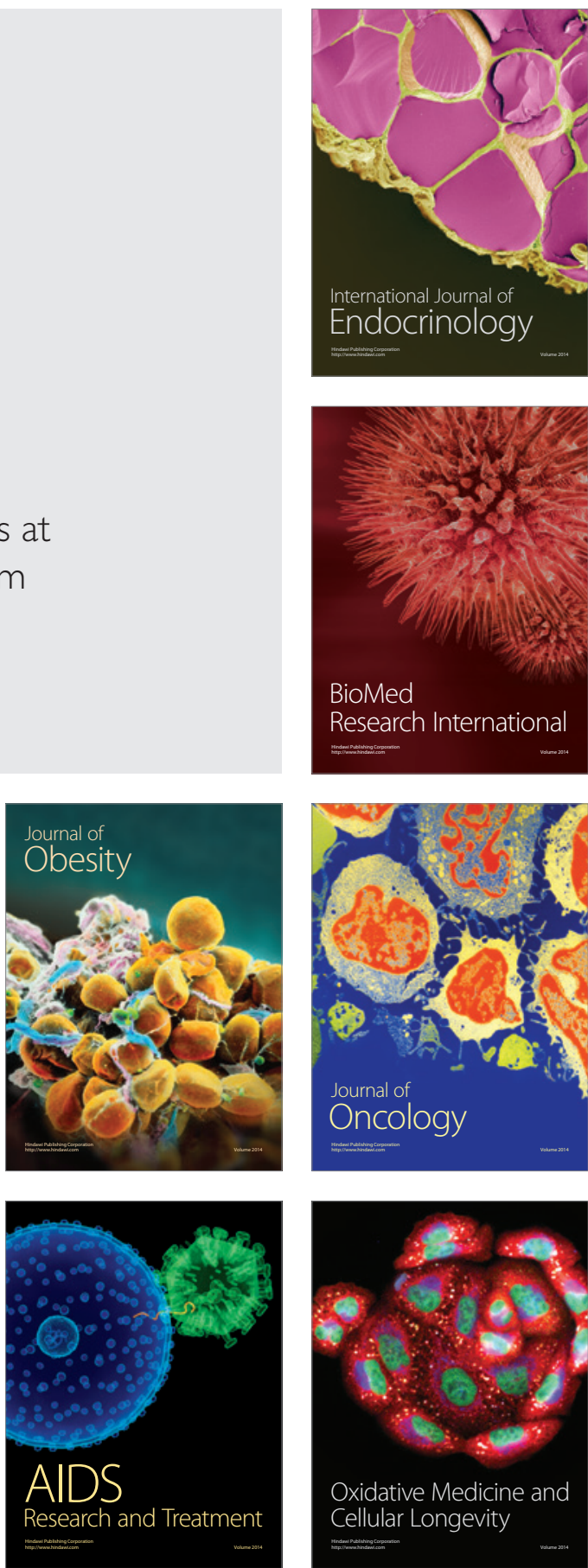